\title{
A critical analysis of the WAQ: Development of a Korean Form
}

\section{Introduction}

Since the confession of pastor William Oates $(1968,1971)$ that he was addicted to work, it is well known that workaholism, defined as an "uncontrollable need to work", is a very harmful disease not only for the person's health and happiness, but also for their social relationships (in family, at workplace, and in larger society) (Fassel 1990; Levy 2015; Robinson 1998). However, workaholism does not simply mean overworking or hard-working; it is an insidious, progressive, and fatal disease (Fassel 1990; Schaef 1987). The notorious 'karoshi' (death from overwork) in Japan or in Korea is attributed to the inevitable result of this workaholism that over time becomes detrimental to personal health, social relations, and organizational soundness (Fassel 1990; Robinson 1996, 1998; Schaef \& Fassel 1988). Falling into the illusion of control, workaholics frequently become perfectionists who obtain self-worth or self-identity from their job. However, when they are not working, they feel anxious, unstable, guilty, and empty within (Robinson 1998; Schaef \& Fassel 1988).

In this regard, three aspects seems critical in defining the dynamic, insidious nature of workaholism: First, the aspect of the compulsiveness or inner drive to work for identitybuilding; second, the aspect of the obsessive increase of work performance for satisfaction despite work-life conflicts, often tolerating everyday personal conflicts (in health, relationship, and responsibility); and third, the aspect of withdrawal symptoms when not working.

In line with this observation, many researchers have tried to develop measurement tools of workaholism (cf. Urbán et al. 2019). There are two relatively recently developed instruments, the Dutch Work Addiction Scale (DUWAS) (cf. Schaufeli et al. 2009), and the Bergen Work Addiction Scale (BWAS) (cf. Andreassen et al. 2012). The former is mainly based on the WorkBAT (Spence \& Robbins 1992) and the WART (Robinson 1998); and the latter on the components model of work addiction (Brown 1993; Griffith 2005). Before these European scales, two American measures had been most widely used in assessing prevalent workaholism: the WorkBat by Spence \& Robbins (1992), and the WART by Robinson (1998). However, both had common shortcomings of lacking validity, and also of using just limited homogeneous samples, which in turn considerably restricted the possibility of generalization (Aziz et al. 2013; McMillan et al. 2002). In addition, each measure had an unstable factor 
structure, validating only parts of the original components, two of three in the WorkBat (Andreassen et al. 2007; Kanai \& Wakabayashi 2001), and three of five in the WART (Clark et al. 2010; Flowers and Robinson 2002). To overcome these limitations, Aziz et al.(2013) developed a new comprehensive measure for workaholism, the Workaholism Analysis Questionnaire (WAQ), which provided the motive for this study.

The WAQ by Aziz et al. (2013) is a 29-item questionnaire that utilizes a 5-point Likert scale. In its conceptualization, it even included items reflecting work-life imbalance, as this allegedly represents a shared symptom of addictive diseases. They derived five workaholism components based on a comprehensive literature review: work-life conflict (WLC), work perfectionism (WP), work addiction (WA), unpleasantness (UP), and withdrawal symptoms (WD). According to them, it was the first research to work out a better workaholism measure psychologically tested on a heterogeneous working population. They reported that their WAQ has proven appropriate enough in terms of internal reliability as well as various kinds of validities in measuring workaholism.

Although Aziz et al.(2013) believed they had confirmed the reliability, as well as the validities of their WAQ, the current paper presents its restrictiveness in terms of generalizability, especially when applying to those people out of different mindsets or cultures. Several limitations of the WAQ can be summarized as follows.

(1) The five-factor structure of the WAQ, i.e., work-life conflict, work perfectionism, work addiction, unpleasantness, and withdrawal symptoms, does not seem to reflect or, at least, name the essential process of workaholism. If the workaholism is defined as an unmanageable intrinsic drive to work that is over time detrimental to health and relationships (Oates 1971; Robinson 1998), the essential construct of workaholism should include such components as compulsive dependency on work, illusion of control, tolerance of conflicts, denial of one's own addiction, and withdrawal symptoms (Fassel 1990; Robinson 1998; Schaef 1988). In this respect, those WAQ-factors, such as work-life conflict and unpleasantness, are in themselves not critical aspects of workaholism. These might rather be negative consequences of it. Workaholism is by definition a disease that is obsessive with work, despite work-life imbalance or conflict. In this case, a new naming like 'endurance of work-life conflict' instead of 'work-life conflict' per se would be more appropriate to conceptualize workaholism as a process addiction (Schaef \& Fassel 1988). Moreover, workaholism can be either a result of a dysfunctional family of origin, or a cause for present familial conflicts (Robinson 1989, 1996, 1998). As a result, several items signalizing the 
breakdown of intimate relationships had better be excluded from components of the workaholism construct.

(2) It seems awkward that the WAQ entails the factor name 'work addiction' as part of its construct, for the terms 'workaholism' and 'work addiction' indicate, in their deep sense, the same behavioral disorder (Oates 1971; Quinones 2018; Robinson 1998; Schaufeli et al. 2009). They seem to indicate the compulsiveness towards work. A renaming as 'compulsive dependency on work', instead of 'work addiction', would be better.

(3) Some items seem overlapping, or even superfluous. For example, items 23, 28, and 29 overlap, at least partially. Item 13 ("I feel very addicted to my work") that asks directly about work addiction might be superfluous, when there are other indirect essential questions.

(4) According to statistical factor analysis, some items seem to be inappropriate to be included in a certain factor. For example, item 9 ("I have a need for control over my work"), has too weak correlation (.29) to the factor 'work addiction' to be included (Aziz et al. 2013: 78). Item 1 ("I feel stressed out when dealing with work issues") belongs to 'job stress', rather than to workaholism (cf. Porter 2001).

(5) Moreover, the five-factor structure of WAQ showed an unacceptable or inadequate model-fit as a whole. Before conducting EFA in order to extract relevant items and factors of the workaholism scale in Korea, this study performed a CFA on the previously proposed model of the WAQ with 29 items and five factors by Aziz et al. (2013). The fit indices of the five-factor solution of the WAQ showed inadequate fit to the Korean data: $\chi^{2}=14,238$, $\mathrm{df}=$ $359, \mathrm{p}<.001 ; \mathrm{RMR}=.056, \mathrm{AFGI}=.724, \mathrm{NFI}=.766, \mathrm{CFI}=.771 ; \mathrm{TLI}=.746 ; \mathrm{RMSEA}$ $=.094$. According to Brown (2006), the best model-fit is to obtain RMR or RMSEA $<.05$, and at the same time, AFGI, NFI, CFI, and TLI $>.90$. The preliminary results from the CFA unarguably imply that the measurement model has certain room for improvement.

(6) Last but not least, the same measure can be differently experienced among people in different socio-cultural backgrounds. It is not only a problem of translation of the English questionnaire into another language, but also a problem of context within which people are feeling, thinking, and working. It might be no surprise, given that the homogeneity of Korean society is considerably greater than many other societies, especially those in the West, and in particular the US (Kohls 2001). This implies that the WAQ could be considerably restructured by processing the Korean national data.

\section{Exploratory Factor Analysis of the WAQ's 29-items}


In the first step, the current study conducted an exploratory factor analysis (EFA) on the WAQ's 29-items, using the first Korean representative sample $(\mathrm{N}=4,242)$. Originally, the 17th Korean Labor and Income Study Panel was administered to 7,199 workers, and it was the first and the only national data survey of workaholism in Korea. However, the following samples had to be excluded systematically in the process of improving statistical effectiveness: (a) The samples from students or unpaid family workers, (b) Those under 20 or over 70 years of age, and (c) The samples with missing values in relevant variables. This data-cleaning process reduced the number of effective samples from 7,199 to 4,242.The final data in the present study consisted of 4,242 respondents of age (20-70) working in a variety of economic sectors in South Korea. They were employed either voluntarily or involuntarily, either regularly or irregularly. There were 1,745 females (41.1\%) and 2,497 males (58.9\%), and their mean age was 39 . Table 1 shows the demographical characteristics and hours worked per week of the sample respondents.

Table 1. Demographic characteristics of the sample.

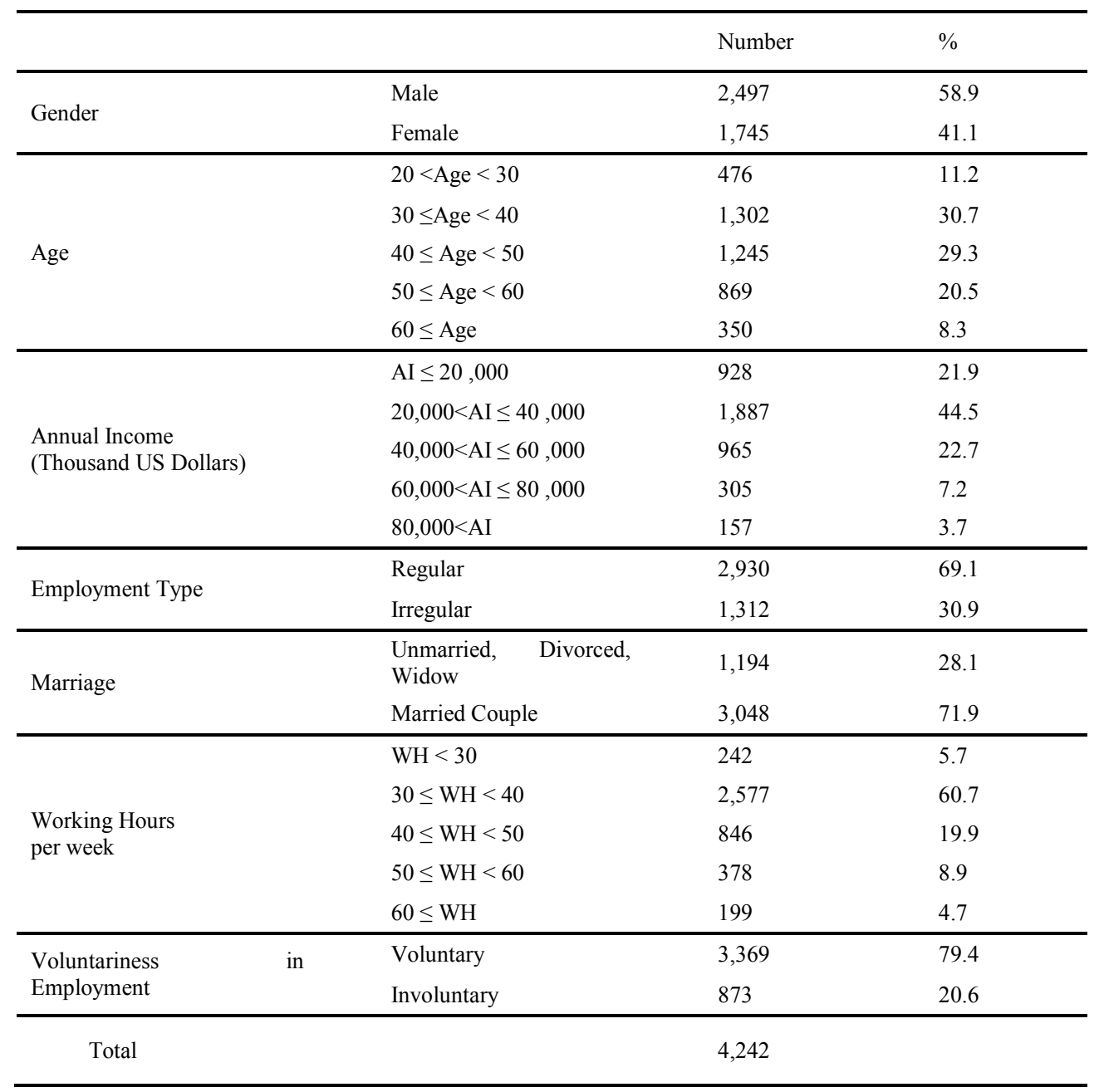


First, the WAQ-Korean form was developed by elaborating the 29-item WAQ of Aziz et al. (2013) by translation-backtranslation, and evaluated by five volunteer experts in terms of suitability for the Korean culture. The volunteers were lecturers or researchers in psychology and labor studies. Six items were omitted, as they were either irrelevant in Korean society, or seemed to be inappropriate to construe workaholism. For example, items 23, 28, and 29 (all related to intimate relationships) seemed rather to be the negative consequences or even deep background of workaholism (McMillan et al. 2004; Robinson 1998; Robinson \& Post 1997), rather than constructive elements of it. Furthermore, items like 1, 8, and 27 (all related to the workaholic system) were likely to reflect the longest working culture in Korean society, rather than to represent workaholism per se(Schaef \& Fassel 1988).Although the Korean government has lowered its legal maximum working hours from 68hours a week to 52 hours from July 2017, to date there is little evidence that shows that people are in practice working less, not to speak of the generally strong workaholic tendency in the whole society since the 1960s (Kang 2000).

Secondly, according to the result of the EFA, this study could eliminate eight relatively irrelevant items $(6,7,9,10,11,16,17,21)$ from the original WAQ. Namely, items with pattern coefficients smaller than .50 were omitted to determine the saliency of significant items with the factors. This EFA was conducted with the method of maximum likelihood (ML) and oblique factor rotation, instead of principal component analysis, as it seemed that certain correlations were existent among the components of workaholism (cf. Brown 2006; Costello \& Osborne 2005; Jolliffe 2011).

The final version of the Korean scale was determined according to the factor loadings and the expert opinions. Through this strict examining process by experts, the content validity of the WAQ-Korean form was reconfirmed. As many researchers indicated similarly (Fassel 1990; Flowers \& Robinson 2002; Schaef 1987; Scott et al. 1997), such factors as compulsive dependence on work (CD), illusion of control (IC), endurance of work-family conflict (EC), along with withdrawal symptoms (WS), were extracted as essential factors for explaining workaholism in Korea. While the $\mathrm{CD}$ and WS represent the quintessential aspects of workaholism, as the workaholism progresses, the IC, as well as EC, shows up more intensively, and much stronger (Fassel 1990; McMillan et al. 2001; Robinson 1998; Schaef 
1987; Schaef \& Fassel 1988). The four-factor structure of workaholism in this study seemed to adequately represent the underlying essential dimensions of work addiction.

The Cronbach's $\alpha$ that shows the internal consistency of the scale was .895 . The split-half reliability coefficient of the new scale was .72. As a result, the present study could preliminarily obtain 15 items suitable to measure workaholism in Korea (Table 2).

Table 2. Oblique Factor Analysis of the Korean WAQ.

\begin{tabular}{|c|c|c|}
\hline \multirow[t]{2}{*}{ Item } & Factor & Factor \\
\hline & \multicolumn{2}{|l|}{ loading } \\
\hline 3. I feel anxious when I am not working. & .95 & Withdrawal \\
\hline 4. I feel bored or restless when I am not working. & .85 & Symptoms (WS) \\
\hline 2. I feel guilty when I am not working. & .78 & $(\mathrm{EV}=6.2, \alpha=.89)$ \\
\hline 5. I am unable to relax at home due to preoccupation at work. & \multicolumn{2}{|l|}{.51} \\
\hline 25. I often put issues in my personal life "on hold" because of work demands. & .97 & \multirow{3}{*}{$\begin{array}{l}\text { 2. Endurance of Work- } \\
\text { Life Conflict (EC) } \\
(\mathrm{EV}=1.7, \alpha=.87)\end{array}$} \\
\hline 26. I often miss out on important personal activities because of work demands. & .86 & \\
\hline 24. My work often seems to interfere with my personal life. & .62 & \\
\hline 19. I frequently check over my work many times before I finish it. & .82 & \multirow{4}{*}{$\begin{array}{l}\text { 3. Illusion of Contro } \\
\text { (IC) } \\
(\mathrm{EV}=1.5, \alpha=.79)\end{array}$} \\
\hline 18. I often obsess about goals or achievements at work. & .68 & \\
\hline 22. It takes me a long time to finish my work because it must be perfect. & .65 & \\
\hline 20. I ask others to check my work often. & .54 & \\
\hline 14. I find myself unable to enjoy other activities because of my thoughts of work. & .79 & Compulsive \\
\hline 12. I frequently have work-related insomnia. & .72 & Dependency on Work \\
\hline 13. I feel very addicted to my work. & .69 & $(\mathrm{CD})$ \\
\hline 15. I consider myself to be a very aggressive person. & .61 & $(\mathrm{EV}=1.2, \alpha=.83)$ \\
\hline \multicolumn{3}{|c|}{$\begin{array}{l}\mathrm{KMO}=.899, \chi^{2}=32735.2, \mathrm{p}<.001, \text { Factor Extraction Method=Maximum Likelihood, Rotation Method=Oblique (Direct } \\
\text { Oblimin) with Kaiser Normalization, Total Variance Explained }=60.9 \%, \text { Cronbach's } \alpha=.895(\mathrm{~N} \text { of items }=15, \mathrm{p}<.01) .\end{array}$} \\
\hline
\end{tabular}

\section{Confirmatory Factor Analysis of the Korean WAQ 15-items}

In the second step, the current study carried out a confirmatory factor analysis (CFA), using a structural equation model (SEM), on the Korean form of 15-WAQ items, to determine the validity and reliability of the new construct. As noted before, the four-factor structure of the Korean WAQ seemed quite different from the five-factor model of Aziz et al. (2013) in the USA, and proved to be even better in terms of statistical significance (cf. Table 5).

The confirmatory factor analysis (CFA) produced the following results. Although CMIN/DF $(=15.946, \mathrm{p}<.001)$ was relatively high, all the indices for model-fit indicated that 
this measurement model was statistically appropriate and acceptable. Table 3 shows that all the standardized regression weights $(\beta)$ were more than $.5(\beta>.5)$, all the average variance extracted (AVE) were larger than .5 (AVE> .5), and all the construct reliabilities were greater than .7 (C.R.> .7). The AVE provides an estimate regarding to what extent the item variance comes from the concerning construct. The construct reliability (C.R.) is substantially similar to the Cronbach's alpha coefficient for the reliability of the related items in the model (Pratarelli \& Browne 2002). Consequently, the convergent reliability, as well as internal consistency, of the workaholism construct was statistically confirmed.

Table 3.Convergent Reliability and Internal Consistency of the new construct.

\begin{tabular}{|c|c|c|c|c|c|c|c|}
\hline Factor $\rightarrow$ Item & B & s.e. & C.R. & $\bar{\beta}$ & AVE & $\begin{array}{l}\text { Construct } \\
\text { Reliability }\end{array}$ & $\begin{array}{l}\text { Cronbach's } \\
\text { Alpha }\end{array}$ \\
\hline WS $\rightarrow 5$ & 1.00 & & & .72 & \multirow{4}{*}{.77} & \multirow{4}{*}{.93} & \multirow{4}{*}{.89} \\
\hline WS $\rightarrow 2$ & 1.13 & .02 & 48.58 & .78 & & & \\
\hline WS $\rightarrow 4$ & 1.29 & .02 & 53.93 & .86 & & & \\
\hline WS $\rightarrow 3$ & 1.41 & .03 & 55.87 & .90 & & & \\
\hline $\mathrm{IC} \rightarrow 20$ & 1.00 & & & .63 & \multirow{4}{*}{.58} & \multirow{4}{*}{.85} & \multirow{4}{*}{.79} \\
\hline IC $\rightarrow 22$ & 1.31 & .04 & 36.03 & .73 & & & \\
\hline $\mathrm{IC} \rightarrow 18$ & 1.46 & .04 & 36.56 & .74 & & & \\
\hline IC $\rightarrow 19$ & 1.52 & .04 & 35.27 & .70 & & & \\
\hline $\mathrm{CD} \rightarrow 15$ & 1.00 & & & .62 & \multirow{4}{*}{.72} & \multirow{4}{*}{.91} & \multirow{4}{*}{.83} \\
\hline CD $\rightarrow 13$ & 1.46 & .04 & 39.68 & .80 & & & \\
\hline CD $\rightarrow 12$ & 1.36 & .04 & 37.82 & .74 & & & \\
\hline CD $\rightarrow 14$ & 1.31 & .03 & 39.71 & .80 & & & \\
\hline $\mathrm{EC} \rightarrow 24$ & 1.00 & & & .72 & \multirow{3}{*}{.75} & \multirow{3}{*}{.90} & \multirow{3}{*}{.87} \\
\hline EC $\rightarrow 26$ & 1.21 & .02 & 52.98 & .86 & & & \\
\hline $\mathrm{EC} \rightarrow 25$ & 1.35 & .03 & 54.33 & .92 & & & \\
\hline
\end{tabular}

* C.R. $=$ Critical Ratio $>1.96 ; \beta>.5 ;$ AVE $>.5$; Construct Reliability $>.7$.

On the other hand, this study also examined the discriminative reliability of the construct, by comparing AVE and correlation coefficients $(\rho)$ of the factors. All the AVE were greater than the square of $\rho\left(\rho^{2}\right)$, respectively, validating the discriminative reliability of the construct (Table 4). 
Table 4. Correlations among factors and discriminative reliability $(\mathrm{N}=4,242)$.

\begin{tabular}{llllll}
\hline & WS & IC & CD & AVE & Maximum $\rho^{2}$ \\
\hline IC & .500 & .537 & .583 & .288 \\
\hline CD & .646 & .537 & & .715 & .417 \\
\hline EC & .381 & .465 & .493 & .751 & .243 \\
\hline WS & & .500 & .646 & .767 & .417 \\
\hline
\end{tabular}

* All the $\mathrm{p}$-values of the correlation coefficients were $<.05 ; \mathrm{AVE}>\rho^{2}$

As noted above, Table 5 shows the difference in model fit indices between the five-factor model and the four-factor model in the current study. It is obvious that the four-factor model in the present study fits much better in measuring workaholism in Korea.

Table 5. Model Comparison between the Five-factor (Aziz et al. 2013) and Four-factor Models.

\begin{tabular}{lllllllllll}
\hline Model & TVE* & $\chi^{2}(\mathrm{CMIN})$ & $\mathrm{df}$ & $\mathrm{RMR}$ & $\mathrm{GFI}$ & AGFI & NFI & TLI & CFI & RMSEA \\
\hline $\begin{array}{l}5 \text {-factor } \\
\text { model }\end{array}$ & $52.8 \%$ & 14,238 & 367 & .056 & .767 & .724 & .766 & .746 & .771 & .094 \\
\hline $\begin{array}{l}\text { 4-factor } \\
\text { model }\end{array}$ & $60.9 \%$ & 1,339 & 84 & .031 & .960 & .942 & .959 & .952 & .962 & .059 \\
\hline
\end{tabular}

* TVE $=$ Total Variance Explained.

\section{Discussion and Implication}

Through this study, it became clear that the five-factor model of workaholism by Aziz et al. (2013) is inadequate for evaluating workaholism in Korea. The factor analyses (CFA, EFA) yielded an adequate four-factor model of workaholism construct. This is very similar to results from previous research that proposed a four-factor model, even though with different items or component namings (cf. Flowers \& Robinson 2002; Robinson et al. 2001; Urbán et al. 2019).

Through this study, the original WAQ has been considerably improved: not only parsimoniously simplified, but also increased in its validity. The analysis with structural equation modeling (SEM) revealed that the WAQ-Korean Form consists of 15 items and four factors (CD, IC, EC, and WS) with optimal convergent validity and discriminative validity. The renewed scale has high internal reliability (alpha $=.90, \mathrm{p}<.01$ ). Therefore, I come to the 
conclusion that the new scale is a reliable as well as valid tool for Korea to measure the prevailing workaholism.

The present study has several theoretical and methodological implications. First, through this study one of the essential aspects of workaholism, the compulsive dependence on work, is clearly replicated. As Robinson (1998) defines, workaholism is the "overindulgence in and preoccupation with work", which is detrimental to work-life balance and health. McMillan et al. (2001) also regarded workaholism as a "personal reluctance to disengage from work", which is provable by the compulsion to work (cf. Ersoy-Kart 2005), regardless of place or time. Almost all the researchers in the area of workaholism agree to include this aspect of compulsive dependency on work in defining workaholism, even though there are still discrepancies in definitions of workaholism (Atroszko et al. 2018; Griffiths et al. 2018; Harpaz \& Snir 2003; Quinones 2018). In the present study, the compulsiveness dimension of the WAQ, i.e., the "work addiction" factor in Aziz et al. (2013), was well extracted as CD, if with different items correlated. This indicates that work-addicted people may be incessantly driven by something inside to work, to excessive extent (Fassel 1990; Harpaz \& Snir 2003; Robinson 1998; Spence \& Robbins 1992). Further, this dimension relates, as the addiction insidiously progresses and deepens, more and more to other dimensions, such as endurance of everyday conflicts to enjoy the drug 'work', either as stimulant or as sedative (EC), or illusion of control to secure their drug 'work' (IC), and withdrawal symptoms without the drug 'work' (WS).

Second, however, the most important question in this context is why people "voluntarily devote" their time and energy to working so obsessively, as Ersoy-Kart (2005) asked, despite all the work-life conflicts, sometimes even to their death. Work-addicts tend to "deny", or to "rationalize", their obsessive work habits, to "feel better" (Fassel 1990; Robinson 1998; Schor 1992). To be exact, they rather become addicted to work, in order not to feel what is going on within and around them (Heide 2009; Schaef \& Fassel 1988). This might be because they are not stable in their deep psyche, but possessed by fear (Burke 2000). That is the fear of failure in survival or in secular success, including social or organizational recognition. They often have vulnerable autonomy, low self-esteem, and volatile sobriety (Burke 2004; Clark et al. 2010; Robinson 1998). Although nobody is free from the performance-oriented societal climate, and thus from the external societal pressure to work incessantly and excessively (Kemeny 2002), it is apparent that work-addicts have an uniquely strong intrinsic drive to overwork. This implies that the workaholics have experienced certain trauma, collectively or 
individually, so that they had to internalize the external pressure in order to survive (Gruen 2007; Heide 2009; Herman 1992). However, little theoretical attention has been paid to this significant aspect. Further discussions are needed at this point.

Third, in order to elucidate this relationship between trauma and addiction, we might need to take quite a different approach to workaholism than the conventional psychological or clinical one: a trans-disciplinary approach, as suggested by Quinones (2018). She emphasizes the macro factors affecting the work addiction. In this respect it seems highly relevant to investigate how a society as a whole has historically experienced the modernization process towards a work-society, in which work has become a central value in the lives of people (cf. Heide 2009; Schor 1992; Thompson 1967).

Fourth, one of the implications this insight has is that just self-reporting assessment of workaholism would have considerable limitations. As a consequence, "using observational and questionnaire tools together" would be highly desirable (Aziz et al. 2013). Moreover, as shown above, some items seem neither meaningful, nor applicable, to many respondents working in special cultures. For this reason, different measure tools may be necessary for heterogeneous respondent groups with unique social and historical contexts respectively.

Fifth, what is also significant from this study is that any scale for assessing workaholism should include specific self-defense mechanisms to sustain the addictive work pattern. In the present study, such factors as endurance of work-life conflict and illusion of control functioned as defensive mechanisms to sustain and perpetuate the work addiction. This may be because, on the one hand, workaholics obtain their identity or self-worth from work (Flowers \& Robinson 2002; Oates 1971); while on the other hand, they tend to avoid feeling the pain of their reality by getting hooked, consciously or unconsciously, onwork (Fassel 1990; Robinson 1998; Schaef \& Fassel 1988). Therefore, people can be so compulsively dependent on work that they enjoy overworking, despite everyday work-life conflicts. They willingly endure all the conflicts between work and life, by feeling contented with their work. In other cases, they hide themselves behind work, in order to avoid confronting their conflicting reality. Furthermore, they try to control their life reality, either at work or at home, by deliberately organizing their time, energy, feeling, and emotion in certain directions. They often deny their painful reality, rationalizing their work addiction. Without work, they feel depressed and extremely powerless, occasionally leading to suicide.

Lastly, this study has some limitations, and thus proposes ideas for future research. Above all, although the current study provides a preliminary Korean version of the WAQ, by 
reconstructing the original WAQ by Aziz et al. (2013), this validation research was based upon the first and the sole data set investigating workaholism on a national level, given that the Korean Labour and Income Panel Study has from 2015 no longer surveyed workaholism. Therefore, it is necessary to validate it subsequently with another panel data, in order to develop and create a better assessment tool of workaholism.

In addition, further empirical research is necessary, based on the Korean form of 15-item WAQ validated in the current study, to highlight those correlations among workaholism, social relationships, and organizational effectiveness. For example, it would be significant to examine how such factors as dissatisfaction with social relationships or organizational identification are related to increasing workaholism (cf. Avanzi et al. 2012). In addition to this variable-centered research, person-centered research based on the new scale is also needed (cf. Gillet et al. 2018). Such research would contribute to reducing and overcoming the fatal disease of working people.

Moreover, as mentioned above, a trans-disciplinary approach is urgent to integrate both micro-level and macro-level insights on workaholism. Otherwise, much research, though well-intended, could merely play a role as a "co-dependent in the addictive system" that systematically promotes workaholism, which all together would help perpetuate the problem (Schaef \& Fassel 1988), not ameliorate it.

\section{References}

Andreassen, C. S., Griffiths, M. D., Hetland, J., \& Pallesen, S. (2012). Development of a Work Addiction Scale. Scandinavian Journal of Psychology, 53(3), 265-272.

Andreassen, C.S., Hetland, J., Pallesen, S. (2013). Psychometric assessment of workaholism measures. Journal of Managerial Psychology,29(1), 7-24.

Andreassen, C. S., Schaufeli, W. B., \& Pallesen, S. (2018). Myths about "The myths about work addiction" Commentary on: Ten myths about work addiction (Griffiths et al., 2018). Journal of behavioral addictions, 7(4), 858-862.

Andreassen, C. S., Ursin, H., \& Eriksen, H. R. (2007). The relationship between strong motivation to work,"workaholism", and health. Psychology and Health, 22(5), 615-629.

Atroszko, P. A., Demetrovics, Z., \& Griffiths, M. D. (2019). Beyond the myths about work addiction: Toward a consensus on definition and trajectories for future studies on problematic overworking: A response to the commentaries on: Ten myths about work addiction (Griffiths et al., 2018). Journal of behavioral addictions, 8(1), 7-15. 
Avanzi, L., van Dick, R., Fraccaroli, F., \& Sarchielli, G. (2012). The downside of organizational identification: Relations between identification, workaholism and well-being. Work \& Stress, 26(3), 289-307.

Aziz, S., Uhrich, B., Wuensch, K. L., \& Swords, B. (2013). The Workaholism Analysis Questionnaire: Emphasizing work-life imbalance and addiction in the measurement of workaholism. Journal of Behavioral and Applied Management, 14(2), 71-86.

Brown, R. I. F. (1993). Some contributions of the study of gambling to the study of otheraddictions. in W. R. Eadington \& J.J. Cornelius (Eds.), Gambling behavior and problem gambling (pp.241272). Reno, NV: University of Nevada Press.

Brown, T. A. (2006). Confirmatory factor analysis for applied research. N.Y.: Guilford Press.

Burke, R. J. (2000). Workaholism in organizations: The role of personal beliefs and fears. Anxiety, Stress and Coping, 13(1), 53-64.

Burke, R. J. (2004). Workaholism, self-esteem, and motives for money. Psychological Reports, 94(2), 457-463.

Clark, M. A., Lelchook, A. M., \& Taylor, M. L. (2010). Beyond the big five: How narcissism, perfectionism, and dispositional affect relate to workaholism. Personality and Individual Differences, 48, 786-791.

Costello, A. B., \& Osborne, J. (2005). Best practices in exploratory factor analysis: Four recommendations for getting the most from your analysis. Practical assessment, research, and evaluation, 10(1), 7, 1-9.

Ersoy-Kart, M. (2005). Reliability and validity of the workaholism battery (Work-BAT): Turkish form. Social Behavior and Personality: an international journal, 33(6), 609-618.

Fassel, D. (1990). Working ourselves to death: The high cost of workaholism, the rewards of recovery. San Francisco: Harper.

Flowers, C. P., \& Robinson, B. (2002). A structural and discriminant analysis of the Work Addiction Risk Test. Educational and Psychological Measurement, 62(3), 517-526.

Gillet, N., Morin, A. J., Sandrin, E., \& Houle, S. A. (2018). Investigating the combined effects of workaholism and work engagement: A substantive-methodological synergy of variable-centered and person-centered methodologies. Journal of Vocational Behavior, 109, 54-77.

Griffiths, M. D. (2005). A 'components' model of addiction within a biopsychosocial framework. Journal of Substance Use, 10(4), 191-197.

Griffiths, M. D., Demetrovics, Z., \& Atroszko, P. A. (2018). Ten myths about work addiction. Journal of Behavioral Addictions, 7(4), 845-857.

Gruen, A. (2007). The insanity of normality: Toward understanding human destructiveness. Berkeley, CA: Human Development Books.

Heide, H. (2009). Globalization of the Work Society. Proposal for a Re-Interpretation of the Work Society as a Posttraumatic Syndrome, in Trans-Humanities, 1(1), 9-38.

Herman, J. L. (1992). Trauma and recovery: The aftermath of violence-from domestic abuse to 
political terror. N.Y.: Basic Books.

Harpaz, I., \& Snir, R. (2003). Workaholism: Its definition and nature. Human Relations, 56(3), 291319.

Jolliffe, I. (2011). Principal component analysis, Berlin: Springer.

Kanai, A., \& Wakabayashi, M. (2001). Workaholism among Japanese blue-collar employees. International Journal of Stress Management, 8(2), 129-145.

Kang, S. D. (2000). Labour relations in Korea between crisis management and living solidarity. InterAsia Cultural Studies, 1(3), 393-407.

Kemeny A. (2002). Driven to excel: A portrait of Canada's workaholics. Canadian Social Trends, 64(2), 2-7.

Kohls, L. R. (2001). Learning to think Korean: A guide to living and working in Korea. Nicholas Brealey.

McMillan, L. H. W., Brady, E. C., O’Driscoll, M. P., \& Marsh, N. V. (2002). A multifaceted validation study of Spence and Robbins' (1992) Workaholism Battery. Journal of Occupational and Organizational Psychology, 75(3).

McMillan, L. H. W., O'Driscoll, M. P., \& Brady, E. C. (2004). The impact of workaholism on personal relationships. British Journal of Guidance and Counseling, 32(2), 171-186.

Levy, D. V. (2015). Workaholism and marital satisfaction among female professionals. The Family Journal, 23(4), 330-335.

Oates, W. E. (1968). On being a 'workaholic'(a serious jest). Pastoral Psychology, 19, 16-20.

Oates, W. E. (1971). Confessions of a workaholic: The facts about work addiction. N.Y.: World Publishing Company.

Porter, G. (2001). Workaholic tendencies and the high potential for stress among co-workers. International Journal of Stress Management, 8(2), 147-164.

Pratarelli, M. E., \& Browne, B. L. (2002). Confirmatory factor analysis of Internet use and addiction. CyberPsychology \& Behavior, 5(1), 53-64.

Quinones, C. (2018). Moving from the terminology debate to a transdisciplinary understanding of the problem: Commentary on: Ten myths about work addiction (Griffiths et al., 2018). Journal of behavioral addictions, 7(4), 880-883.

Robinson, B. E. (1989). Work addiction: Hidden legacies of adult children. Deerfield Beach, FL: Health Communications.

Robinson, B. E. (1996). The psychosocial and familial dimensions of work addiction: Preliminary perspectives and hypotheses. Journal of Counseling \& Development, 74(5), 447-452.

Robinson, B. E. (1998). Chained to the desk: A guidebook for workaholics, their partners and children, and the clinicians who treat them. N.Y.: NYU Press.

Robinson, B. E., Flowers, C., \& Carroll, J. (2001). Work stress and marriage: A theoretical model examining the relationship between workaholism and marital cohesion. International Journal of 
Stress Management, 8(2), 165-175.

Robinson, B. E., \& Post, P. (1997). Risk of addiction to work and family functioning. Psychological Reports, 81(1), 91-95.

Scott, K. S., Moore, K. S., Micelli, M. P. (1997). An exploration of the meaning and consequences of workaholism. Human Relations, 50(3), 287-314.

Schaef, A. W. (1987). When society becomes an addict. N.Y.: Harper Collins.

Schaef, A. W., \& Fassel, D. (1988). The addictive organization. N.Y.: Harper \& Row Publishers.

Schaufeli, W. B., Shimazu, A., \& Taris, T.W. (2009). Being driven to work excessively hard. The evaluation of a two-factor measure of workaholism in the Netherlands and Japan. Cross-Cultural Research, 43(4), 320-348.

Schor, J. (1992). The overworked American: The unexpected decline of leisure. N.Y.: Basic Books.

Spence, J. T., \& Robbins, A. S. (1992). Workaholism: Definition, measurement, and preliminary results. Journal of Personality Assessment, 58(1), 160-178.

Thompson, E. P. (1967). Time, work-discipline, and industrial capitalism. Past \&Present, 38, 56-97.

Urbán, R., Kun, B., Mózes, T., Soltész, P., Paksi, B., Farkas, J., ... \& Griffiths, M. D. (2019). A FourFactor Model of Work Addiction: The Development of the Work Addiction Risk Test Revised. European addiction research, 25(3), 145-160. 